\title{
Satisfaction on Hospital Services in Dhaka Among Heart Disease Patients: A SERVQUAL Modeling Approach
}

\author{
Mohammad Ahsan Uddin ${ }^{1, *}$, Safiullah ${ }^{2}$ \\ ${ }^{1}$ Department of Statistics, University of Dhaka, Dhaka, Bangladesh \\ ${ }^{2}$ Abdul Malek Ukil Medical College \& Hospital, Noakhali, Bangladesh \\ Email address: \\ munna_stat@yahoo.com (M. A. Uddin) \\ ${ }^{*}$ Corresponding author
}

To cite this article:

Mohammad Ahsan Uddin, Safiullah. Satisfaction on Hospital Services in Dhaka Among Heart Disease Patients: A SERVQUAL Modeling Approach. American Journal of Biomedical and Life Sciences. Vol. 9, No. 1, 2021, pp. 1-9. doi: 10.11648/j.ajbls.20210901.11

Received: December 26, 2020; Accepted: January 7, 2021; Published: January 18, 2021

\begin{abstract}
Now-a-days, patients' voice regarding the delivery of health care services is a burning question in the developing countries. It is thought that patients' perceptions towards health services are mostly ignored in these countries by the health service providers. This study, therefore, seeks the service quality factors which are essential to the patients. A field survey was made in this purpose on the heart disease patients in Dhaka city as this disease is very common in Bangladesh. SERVQUAL modeling approach and principal component analysis were considered to make evaluation over hospital facilities and found, overall, dissatisfaction of the patients. The SERVQUAL model is used to assess patients' expectations and perceptions regarding service quality in hospitals. Both expectations and perceptions are measured using a 5-point scale to rate their level of agreement or disagreement (1: strongly disagree and 5: strongly agree), on which the higher numbers indicate higher level of expectation or perceptions. Perceptions are based on the actual service they receive in hospitals are based on experiences and information received about hospital stuffs, doctors or overall hospital maintenance system. Service quality scores are obtained from the difference between the expectation and perception scores which range from -4 to +4 (-4: very dissatisfied, +4 : very satisfied). The quality score measures the service gap, that is, the degree to which the expectations excels perceptions. Binary logistic regression analysis was used to find out significant covariates for occurring heart disease. Also, a Poisson regression model was performed for detecting potential covariates that affect number of hospital visit (s) per year of the heart disease patients. The study found ultimate dissatisfaction of the patients which brings the thought that a powerful managerial orientation might be launched in the hospitals to ensure quality services.
\end{abstract}

Keywords: Heart Disease, SERVQUAL Modeling, Principal Component Analysis, Binary Logistic Regression, Poisson Regression Model

\section{Introduction}

Healthy population is a must for achieving and sustaining economic growth. Appropriate health care facilities play an important role for the developed countries to acquire development objectives [1]. Unfortunately, in Bangladesh, the health facility delivery system is bestowed with various problems. The health care delivery system in Bangladesh is facing three major challenges: improving quality, increasing access, and reducing costs [2]. Though all these threes are important, there is another aspect that the quality of health care services has a big influence on patients' satisfaction.
This study mainly aims to evaluate hospital facilities in the Dhaka city. It is not a surprising news that one of the leading causes of death in Bangladesh is heart attack [3]. According to a recent study in Bangladesh, one out of five adults have hypertension [4]. It appears that the cause of this sharp rise in Bangladesh is due to a change of diet. The development of the culture of eating meat and fish more than vegetables and the westernization of food has led to a surge in heart diseases with an excess intake of salt. Intake of salt per day by adult men in Bangladesh exceeds the WHO standard [5]. As a result of the rapid increase in heart diseases, there is lower availability of medical services for all patients [6]. Now-adays, people are more educated than before in Bangladesh. 
They are getting more conscious of their health, many of them go to the hospitals for regular checkup. They are very much concern about hospital facilities. That's why, a scoping review with goals of evaluating their opinions on hospital facilities is conducted in this study. Since cardiovascular disease is very common in our country and death rate is high on this disease, the evaluation of health care facilities is made on heart patients.

The general aim of the study is to know the patient's satisfaction over different health care services provided by both public and private hospitals. The study explores patients satisfaction or dissatisfaction in getting treatment services along with identifying the expectation and demands of health care towards health practitioners and service providers. In addition, the study also finds the risk factors that are responsible for heart disease which makes the study dynamic. Moreover, the number of hospital visit (s) per year by heart patients is also analyzed in this study and significant accountable risk factors are identified.

\section{Materials and Methods}

A primary data set has been used in this study for analysis purpose. For collecting data, a questionnaire was designed cautiously with respect to study objective. Accurate answer depends on simple and appropriate questionnaire. In the questionnaire, point liker scale questionnaire was used including several questions related to the purpose of the study. In this study, data have been collected through direct interview of the respondents. One individual is interviewed single time with a closer observation for avoiding any sort of asymmetry of information. Due to time and resource constraints, a sample of 300 interviews was taken in this study from Dhaka city. Several statistical techniques are used in this study for data analysis purpose. Regression analysis is a very common statistical method to investigate the relationships between a dependent variable and a set of independent variables [7, 8]. This widely used analysis examines which variables matter most, which variables can be neglected, and how these variables influence each other [9, 10]. There are different types of regression models in the literature for making predictions. Three important facts lead these techniques mostly: type of dependent variables, number of independent variables, and shape of the regression line [11]. If the response vector $Y$ be of binary type, i.e., meaning to whether an event of interest has occurred or not, binary logistic regression is used, which takes the following functional form [12]:

$$
\pi(x)=\frac{e^{x^{\prime} \beta}}{1+e^{x^{\prime} \beta}}
$$

Where $\pi(x)$ represents the conditional mean of $Y$ given $x$ i.e., $E(Y \mid x)$. The unknown parameter $\beta$ is estimated by the method of maximum likelihood estimation $[13,14]$.

SERVIQUAL model has been incorporated in this study to measure the patients' satisfaction on hospital service quality by asking their perception and expectation towards service dimensions. The SERVQUAL framework has guided various studies in the service sector that focuses on hospitals, banks, hotels, repair and maintenance services, telephone companies, physicians, academic institutions and retail stores [15]. Interestingly, while the SERVQUAL framework has been applied with great enthusiasm, empirical support for the proposed framework and the measurements has not always been so strong. But, marketing academics have debated the model and its measures. For example, Oh and Parks [16] have suggested measurement problems in the use of difference scores; Cronin and Taylor [17] have suggested that service quality can be predicted adequately by using perceptions alone rather than using difference scores; and Carman [18] has suggested that in specific service situations, it is important to modify some of the SERVQUAL dimensions or even to introduce new ones. In addition, measuring the gap between expectations and performance in cross-sectional studies may be problematic. As data are usually collected subsequent to the service encounter, questions on service expectations may depend on memory or biased by actual services received [19]. In the context of hospitals, Reidenbach and SandiferSmallwood [20] have shown the existence of measurement problems. In the context of Bangladesh, this study includes additional cultural variables for establishing the criteria of service quality and their measures. For instance, it is suggested by qualitative interviews that the concept of baksheesh (facilitation payments) and discipline should be included in assessing perceptions of service quality. In various service sectors, even the most common services are often not easier to obtain without baksheesh. Sometimes, a patient's fate may be determined by his/her ability to pay baksheesh. Discipline has also broken here for a variety of political, social, and economic reasons, and is found rigidly in various service sectors. Not surprisingly, service quality perceptions have suffered, often drastically, among service seekers. As a result, this study has adopted a modified framework with its attendant measures in lieu of limiting the concepts and measures of service quality to the theoretical structure and measures suggested by the SERVQUAL framework. Though the assessment considered several of the SERVQUAL dimensions were, the introduction of extra factors was also relevant to the assessment of service quality in hospitals in Bangladesh.

The aim of principal component analysis (PCA) is to reduce the number of original variables to a smaller number of uncorrelated variables called principal components which account for the variance in the data as much as possible [21]. It is a widely used statistical procedure for reducing dimension of the data and clustering visualization. Principal component analysis uses an orthogonal transformation to find out principal components, which are a linear combinations of linearly uncorrelated original variables. The obtained principal components account for the most of the variability of the dataset. For the $\mathrm{p}$-component random vector $X$, consider the linear combinations

$$
Y_{1}=l_{11} X_{1}+l_{21} X_{2}+\cdots+l_{P 1} X_{P}
$$




$$
Y_{2}=l_{12} X_{1}+l_{22} X_{2}+\cdots+l_{P 2} X_{P}
$$

And so on where the $Y$ 's are the required principal components which are being extracted using maximization of variance [22].

Poisson regression, which is also known as log-linear model, is a popular method used to predict a dependent variable which consists of 'count data' given one or more independent variables [23]. Poisson regression assumes the dependent variable $Y$ follows a Poisson distribution and the logarithm of expected value of the response variable can be modeled by a linear combination of unknown parameters. If $Y$ be the dependent variable and $x$ be the vector of independent variables, then the Poisson regression takes the form as

$$
\log \left(E\left(\begin{array}{ll}
Y & x
\end{array}\right)\right)=\alpha+\beta^{\prime} x,
$$

Where $\alpha$ is the intercept term and $\beta$ be the vector of regression parameters [24].

Table 1. Binary logistic regression model estimates of the selected covariates for heart disease in Dhaka city along with standard error (SE), odds ratio

\begin{tabular}{|c|c|c|c|c|}
\hline Covariates & Coefficient & SE & OR & p-value \\
\hline Constant & -7.801 & 2.291 & 0 & 0.001 \\
\hline \multicolumn{5}{|l|}{ Gender } \\
\hline female & - & - & - & - \\
\hline male & 2.21 & 1.12 & 9.118 & 0.048 \\
\hline \multicolumn{5}{|l|}{ Age } \\
\hline otherwise & - & - & - & - \\
\hline greater than 50 & 2.489 & 0.335 & 12.044 & $<0.001$ \\
\hline \multicolumn{5}{|l|}{ Smoking status } \\
\hline no & - & - & - & - \\
\hline yes & 3.506 & 1.117 & 33.315 & 0.002 \\
\hline \multicolumn{5}{|l|}{ Diabetes status } \\
\hline no & - & - & - & - \\
\hline yes & -0.104 & 0.325 & 0.901 & 0.749 \\
\hline \multicolumn{5}{|l|}{ Obesity status } \\
\hline no & - & - & - & - \\
\hline yes & 0.802 & 0.322 & 2.229 & 0.013 \\
\hline \multicolumn{5}{|l|}{ Heredity status } \\
\hline no & - & - & - & - \\
\hline yes & 0.059 & 0.318 & 1.061 & 0.853 \\
\hline \multicolumn{5}{|c|}{ Panic disorder status } \\
\hline no & - & - & - & - \\
\hline yes & 0.89 & 0.352 & 2.436 & 0.011 \\
\hline \multicolumn{5}{|l|}{ High BP status } \\
\hline no & - & - & - & - \\
\hline yes & 0.677 & 0.3434 & 1.969 & 0.042 \\
\hline \multicolumn{5}{|c|}{ High cholesterol food } \\
\hline no & - & - & - & - \\
\hline yes & 0.078 & 0.308 & 9.25 & 0.008 \\
\hline
\end{tabular}
$(O R)$, and p-value.

The risk factors that are acting behind to heart disease are shown in Table 1. The variables gender, age, smoking status, obesity status, panic disorder status, high BP status, and high cholesterol food were found significant in the Table while diabetes status and heredity status were insignificant in the model. The variable gender is significant at 5\% level of significance having p-value 0.048. Here, "female" is considered as reference category. A male respondent has 9.118 times significantly higher odds of having record of heart attack compared to female keeping all other variables at a fixed level. The people aged greater than 50 has 12.044 times significantly higher odds of having record of heart attack compared to aged less than 50 and this finding is significant with $p$-value less than 0.001 . The analysis reveals a significant relationship (p-value 0.002) between smoking status and heart disease that a smoker has 33.315 higher odds of having record of heart attack compared to a nonsmoker keeping all other variables at a fixed level. A respondent who is obese, has $(2.229-1) * 100 \%$ or $122.9 \%$ higher odds of having record of heart attack at $5 \%$ significance level (pvalue 0.013 ) compared to the respondent who is not obese. The variable panic disorder is also significant at $5 \%$ level of significance bearing p-value 0.011 . A person with no panic disorder has $(2.436-1) * 100 \%$ or $143.6 \%$ higher odds of having record of heart attack compared to the person having no panic disorder. High BP status is significant in the model having $p$-value 0.042. A respondent with high BP has (1.969$1)^{*} 100 \%$ or $96.9 \%$ higher odds of having record of heart attack compared to the person having no high BP keeping all other variables at a fixed level. Taking high cholesterol food is again a potential covariate in the model at $5 \%$ level of significance (p-value 0.008). A respondent who takes food having high cholesterol, has $(9.25-1) * 100 \%$ or $825 \%$ higher odds of having record of heart attack compared to the respondent who doesn't take high cholesterol food keeping all other variables at a fixed level.

\section{Conceptual Framework}

\subsection{Main Components}

The proposed main components of hospital service quality in Bangladesh are given as follows:

Responsiveness: The literature identifies responsiveness as an essential component of service quality and characterizes it as the willingness of the staffs to be helpful and to provide required services. Six items are used to depict and measure the construct.

Assurance: Assurance is defined as the behaviors and knowledge of the employees which carry a sense of confidence that service outcomes will meet the expectations. Six items are used to measure this construct to reflect capacity, efficiency, and the correctness of services provided to the patients.

Communication: Communication is defined as informing customers in language which they can understand; it also involves listening to them. Communication with patients is an important issue regarding service satisfactions because when hospital staffs take the time to answer questions that concern patients, it can mitigate their feelings of uncertainty. Four items are used to assess the level of communication.

Discipline: Discipline represents as the sense of order in a given service environment that one feels and is reflected in both behaviors of the staff and the figure of the overall hospital environment. In many organizations and institutions in Bangladesh, lack of discipline is diffusive. Employees are often indolent to perform their prescribed tasks and exhibit an affinity to complicate existing rules and regulation. 
Cleanliness is another advent of the extent of order and discipline in the organization. Six items representing aspects of discipline are used to measure the construct.

Baksheesh: Baksheesh is defined as the extra payoff which is expected in many service settings in Bangladesh for 'due' services. Though there is a fine line, it may be distinguished from bribes in that bribes means payments for money to obtain or render 'undue' services. Two items are used to measure Baksheesh.

These five constructs represent the initial set of factors that arisen as latent variables from the exploratory analysis. Services at private and public hospitals are compared along with the measures of these factors.

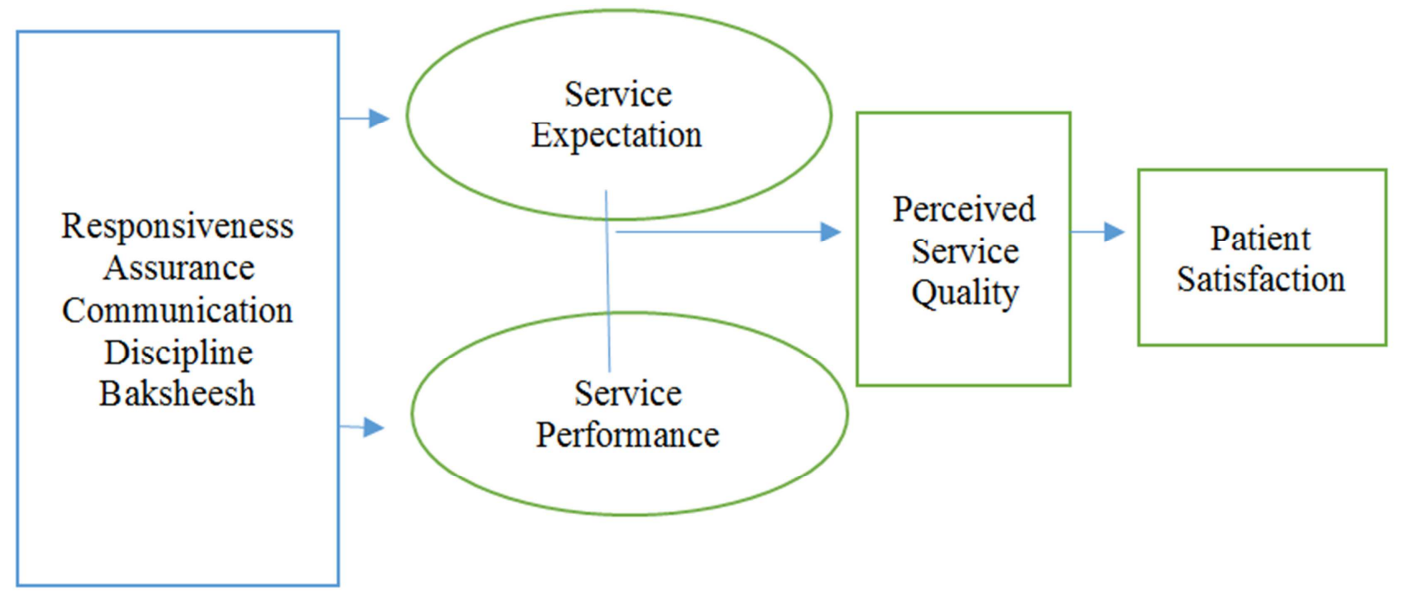

Figure 1. Conceptual framework for the SERVQUAL model.

\subsection{Construction of SERVQUAL Questionnaire}

A preliminary version of the questionnaire was first developed and the items were rated on five-point Likert scales in a structured format with the verbal statements 'strongly disagree' and 'strongly agree' anchored to the numerals 1 and 5. This format is suggested for health care surveys. Multiple items are used to represent each construct and are evaluated for their validity and reliability. The questionnaire was pre-tested several times. As stipulated by the SERVQUAL model, the statements are divided into two parts, the first part seeks to measure the expectations of patients and the second part seeks to measure their perceptions. This questionnaire was discussed with the supervisor and then tested. From the testing, respondents were quite comfortable with the questionnaire unless for some statements like "do hospital staff expect tips" (statement 24). However, the statement was considered in the final questionnaire because it has a great impact on hospital service quality in Bangladesh. SERVQUAL model is used as the basis for the structured questionnaire because it provides information on our research questions in which it is tried to know whether the heart disease patients are satisfied or not with the service quality in hospital by assessing the difference between the expectation and perception of services.

\subsection{Measurement}

The SERVQUAL model is used to assess patients' expectations and perceptions regarding service quality in hospitals. Both expectations and perceptions are measured using a 5-point scale to rate their level of agreement or disagreement (1: strongly disagree and 5: strongly agree), on which the higher numbers indicate higher level of expectation or perceptions. Perceptions are based on the actual service they receive in hospitals are based on experiences and information received about hospital stuffs, doctors or overall hospital maintenance system. Service quality scores are obtained from the difference between the expectation and perception scores which range from -4 to +4 (-4: very dissatisfied, +4 : very satisfied). The quality score measures the service gap, that is, the degree to which the expectations excels perceptions. The more positive the P-E scores are, the higher the level of service quality leading to a higher level of patients' satisfaction. Satisfaction and service quality are both treated together as functions of a patient's perceptions and expectations. In almost all cases, service quality is satisfactory when expectation and perception are equal. In this study, the disconfirmation paradigm is used which is based on the discrepancy theories. According to this paradigm, patient's satisfaction judgments are the result of patient's perceptions of the difference between their perception of performance and their expectations. Negative disconfirmation directs to decreased satisfaction while positive disconfirmation directs to increased satisfaction. This theory has been used to develop questionnaire.

\subsection{Coding}

The SERVQUAL dimensions/items are main variables used in this study and these dimensions/items are coded in order to ease the analysis of collected data. Here is the coding of the variables for analysis. 
Table 2. Coding of the SERVQUAL dimensions.

\begin{tabular}{ll}
\hline SERVQUAL Dimensions/Items & Code \\
\hline & RS1: The staffs are responsive to patients need \\
& RS2: The staffs are caring \\
& RS3: The staffs respond immediately when called \\
& RS4: The staffs are polite \\
RS5: The hospital staffs are helpful & \\
RS6: Service provided has prompt responsiveness \\
AS1: The facility has skilled staff \\
AS2: Services are provided efficiently \\
AS3: Staffs are professional \\
AS4: Medical procedures are correct at the first time \\
AS5: The doctors are competent \\
AS6: The nurses are well trained \\
CM1: The doctors are willing to answer any question \\
CM2: I have received adequate explanation of any test I had to undergo \\
CM3: I am given adequate information about my health condition \\
CMssurance (AS) & DS1: Rules and regulations are strictly maintained \\
& DS2: Cabins or wards are regularly cleaned \\
Communication (CM) & DS3: Toilet facilities are cleaned \\
& DS4: The staffs are disciplined \\
& DS5: Cleanliness is maintained throughout the facility \\
& DS6: The hospital staff have a clean appearance \\
BS1: Service are provided properly without tips \\
BS2: Hospital staffs don't expect tips
\end{tabular}

Table 3. Presentation of obtained SERVQUAL scores.

\begin{tabular}{|c|c|c|c|c|c|}
\hline Dimension & Statement & Expectation score & Perception score & Gap score & Average for Dimensions \\
\hline \multirow[t]{6}{*}{ Responsiveness (RS) } & RS1 & 4.21 & 3.15 & -1.06 & \multirow[t]{6}{*}{-1.05} \\
\hline & RS2 & 4.14 & 3.01 & -1.14 & \\
\hline & RS3 & 4.16 & 2.88 & -1.28 & \\
\hline & RS4 & 4.06 & 3.05 & -1.02 & \\
\hline & RS5 & 4.07 & 3.29 & -0.78 & \\
\hline & RS6 & 4.13 & 3.12 & -1.02 & \\
\hline \multirow[t]{6}{*}{ Assurance (AS) } & AS1 & 3.89 & 3.25 & -0.64 & \multirow[t]{6}{*}{-0.92} \\
\hline & AS2 & 4.25 & 3.24 & -1.01 & \\
\hline & AS3 & 4.07 & 2.98 & -1.09 & \\
\hline & AS4 & 4.26 & 3.30 & -0.96 & \\
\hline & AS5 & 4.33 & 3.57 & -0.76 & \\
\hline & AS6 & 4.01 & 2.96 & -1.05 & \\
\hline \multirow[t]{4}{*}{ Communication (CM) } & CM1 & 4.19 & 2.98 & -1.21 & \multirow[t]{4}{*}{-0.87} \\
\hline & $\mathrm{CM} 2$ & 4.22 & 3.82 & -0.39 & \\
\hline & CM3 & 4.06 & 3.09 & -0.96 & \\
\hline & CM4 & 4.01 & 3.12 & -0.89 & \\
\hline \multirow[t]{6}{*}{ Discipline (DS) } & DS1 & 4.10 & 3.12 & -0.98 & \multirow[t]{6}{*}{-1.11} \\
\hline & DS2 & 4.31 & 3.10 & -1.21 & \\
\hline & DS3 & 4.10 & 2.96 & -1.14 & \\
\hline & DS4 & 4.15 & 3.01 & -1.13 & \\
\hline & DS5 & 4.04 & 3.06 & -0.98 & \\
\hline & DS6 & 4.13 & 2.95 & -1.18 & \\
\hline \multirow[t]{2}{*}{ Baksheesh (BS) } & BS1 & 4.04 & 2.94 & -1.09 & \multirow[t]{2}{*}{-1.10} \\
\hline & $\mathrm{BS} 2$ & 4.04 & 2.93 & -1.10 & \\
\hline
\end{tabular}

\section{Results and Discussions}

In Table 3, expectations and perceptions were both measured using the 5-point Likert scale whereby the higher numbers indicate higher level of expectation or perception. In general, patient expectation exceeded the perceived level of service shown by the perception scores. This gap score
(Perception - Expectation) was negative. According to Parasuraman et al. [25], it is, however, common for consumer's expectation to exceed the actual service perceived and this signifies that there is always need for improvement. The items with the highest expectation scores were doctors' competence (4.33), cleanliness of cabins/wards (4.31), correctness of medical procedures (4.26) and efficiency of provided service (4.25). However, these scores are not very 
different from scores of other items and this implies generally, patients expect very high from hospitals. The items rated highest for actual service perceived were, adequate explanation of any tests (3.82), competency of doctors (3.57), having skilled staff (3.25) and efficiency of service provided (3.24). The gap scores are the difference between the perception and expectation scores with a range of values from -4 to +4 and these gap scores measure hospital service quality and hence patients' satisfaction. The more perceptions are close to expectations, the higher the perceived level of quality. The largest gaps scores were providing service without tips (-1.56), expectation of tips of hospital staffs (-1.56), immediate response of staffs when calls (-1.28), willingness of doctors to answer questions (-1.21) and cleanliness of cabins/wards (1.21). Finally, OSQ (Overall Service Quality) is -1.11 . This negative value implies the patients are not satisfied with overall hospital services.

It is found from Table 4 that communality for "Responsiveness of staffs" variable is.618 which indicates this variable is explaining $61.8 \%$ variation from the factors associated with the study. "Expectation of tips of hospital staffs" is explaining $91.3 \%$ variation from the factors which is the covering the highest variation associated with the study. Here, it is observed that the communalities of all variables ranges from.504 to.913 which means that the component extracted can explain the variables well.
Table 4. Results obtained from PCA analysis.

\begin{tabular}{lll}
\hline & \multicolumn{2}{l}{ Communalities } \\
\cline { 2 - 3 } & Initial & Extraction \\
\hline Responsiveness of staffs & 1.000 & .618 \\
Caring attitude of staffs & 1.000 & .761 \\
Response attitude of staffs & 1.000 & .687 \\
Polite attitude of staffs & 1.000 & .689 \\
Helpful attitude of stuffs & 1.000 & .731 \\
Providing service with prompt responsiveness & 1.000 & .661 \\
Sufficiency of skilled stuffs & 1.000 & .683 \\
Efficiency of provided service & 1.000 & .776 \\
Professionalism attitude of staffs & 1.000 & .636 \\
Correctness of medical process at the first time & 1.000 & .689 \\
Competency of doctor & 1.000 & .504 \\
Competency of nurses & 1.000 & .705 \\
Willingness attitude of doctor & 1.000 & .703 \\
Getting adequate information of undergoing test & 1.000 & .894 \\
Getting adequate information of health & 1.000 & .703 \\
condition & & \\
Getting adequate information of treatment & 1.000 & .720 \\
Maintenance of rules & 1.000 & .767 \\
Cleanliness of cabins & 1.000 & .830 \\
Cleanliness of toilet & 1.000 & .803 \\
Disciplined attitude of staffs & 1.000 & .725 \\
Maintenance of cleanliness & 1.000 & .745 \\
Clean appearance of hospital staffs & 1.000 & .706 \\
Providing service properly without tips & 1.000 & .911 \\
Expectation of tips of hospital staffs & 1.000 & .913 \\
\hline
\end{tabular}

Table 5. Total variance obtained from PCA analysis.

\begin{tabular}{|c|c|c|c|c|c|c|c|c|c|}
\hline \multicolumn{10}{|c|}{ Total Variance Explained } \\
\hline \multirow{2}{*}{ Component } & \multicolumn{3}{|c|}{ Initial Eigenvalues } & \multicolumn{3}{|c|}{ Extraction Sums of Squared Loadings } & \multicolumn{3}{|c|}{ Rotation Sums of Squared Loadings } \\
\hline & Total & $\%$ of Variance & Cumulative \% & Total & $\%$ of Variance & Cumulative \% & Total & $\%$ of Variance & Cumulative \% \\
\hline 1 & 11.153 & 46.469 & 46.469 & 11.15 & 46.469 & 46.469 & 5.07 & 21.144 & 21.144 \\
\hline 2 & 2.035 & 8.481 & 54.95 & 2.035 & 8.481 & 54.95 & 4.38 & 18.275 & 39.419 \\
\hline 3 & 1.727 & 7.197 & 62.147 & 1.727 & 7.197 & 62.147 & 4.3 & 17.951 & 57.37 \\
\hline 4 & 1.613 & 6.72 & 68.867 & 1.613 & 6.72 & 68.867 & 1.95 & 8.131 & 65.5 \\
\hline 5 & 1.033 & 4.302 & 73.169 & 1.033 & 4.302 & 73.169 & 1.84 & 7.669 & 73.169 \\
\hline 6 & 0.865 & 3.605 & 76.774 & & & & & & \\
\hline 7 & 0.67 & 2.791 & 79.565 & & & & & & \\
\hline 8 & 0.572 & 2.384 & 81.949 & & & & & & \\
\hline 9 & 0.532 & 2.215 & 84.164 & & & & & & \\
\hline 10 & 0.503 & 2.097 & 86.261 & & & & & & \\
\hline 11 & 0.501 & 2.086 & 88.347 & & & & & & \\
\hline 12 & 0.407 & 1.694 & 90.041 & & & & & & \\
\hline 13 & 0.386 & 1.61 & 91.651 & & & & & & \\
\hline 14 & 0.304 & 1.266 & 92.917 & & & & & & \\
\hline 15 & 0.264 & 1.101 & 94.019 & & & & & & \\
\hline 16 & 0.243 & 1.014 & 95.032 & & & & & & \\
\hline 17 & 0.212 & 0.881 & 95.914 & & & & & & \\
\hline 18 & 0.205 & 0.853 & 96.767 & & & & & & \\
\hline 19 & 0.191 & 0.794 & 97.561 & & & & & & \\
\hline 20 & 0.154 & 0.641 & 98.202 & & & & & & \\
\hline 21 & 0.14 & 0.581 & 98.783 & & & & & & \\
\hline 22 & 0.113 & 0.471 & 99.255 & & & & & & \\
\hline 23 & 0.102 & 0.424 & 99.679 & & & & & & \\
\hline 24 & 0.077 & 0.321 & 100 & & & & & & \\
\hline
\end{tabular}

Table 5 is showing the Eigen values and percentage of variance in the original variables. From Eigen values of components, it is found that first 5 components' Eigen value is greater than 1 . So, the first 5 components should be considered as 5 factors. Here, the consecutive first five factors are explaining $46.469 \%, 8.481 \%, 7.197 \%, 6.72 \%$, and
$4.302 \%$ of variation of data set, respectively. These five factors altogether can explain $73.169 \%$ of variation which is nearly $80 \%$ of total variation of the data set. It means if these five factors are considered, only $26.831 \%$ information of the data set will be lost. 


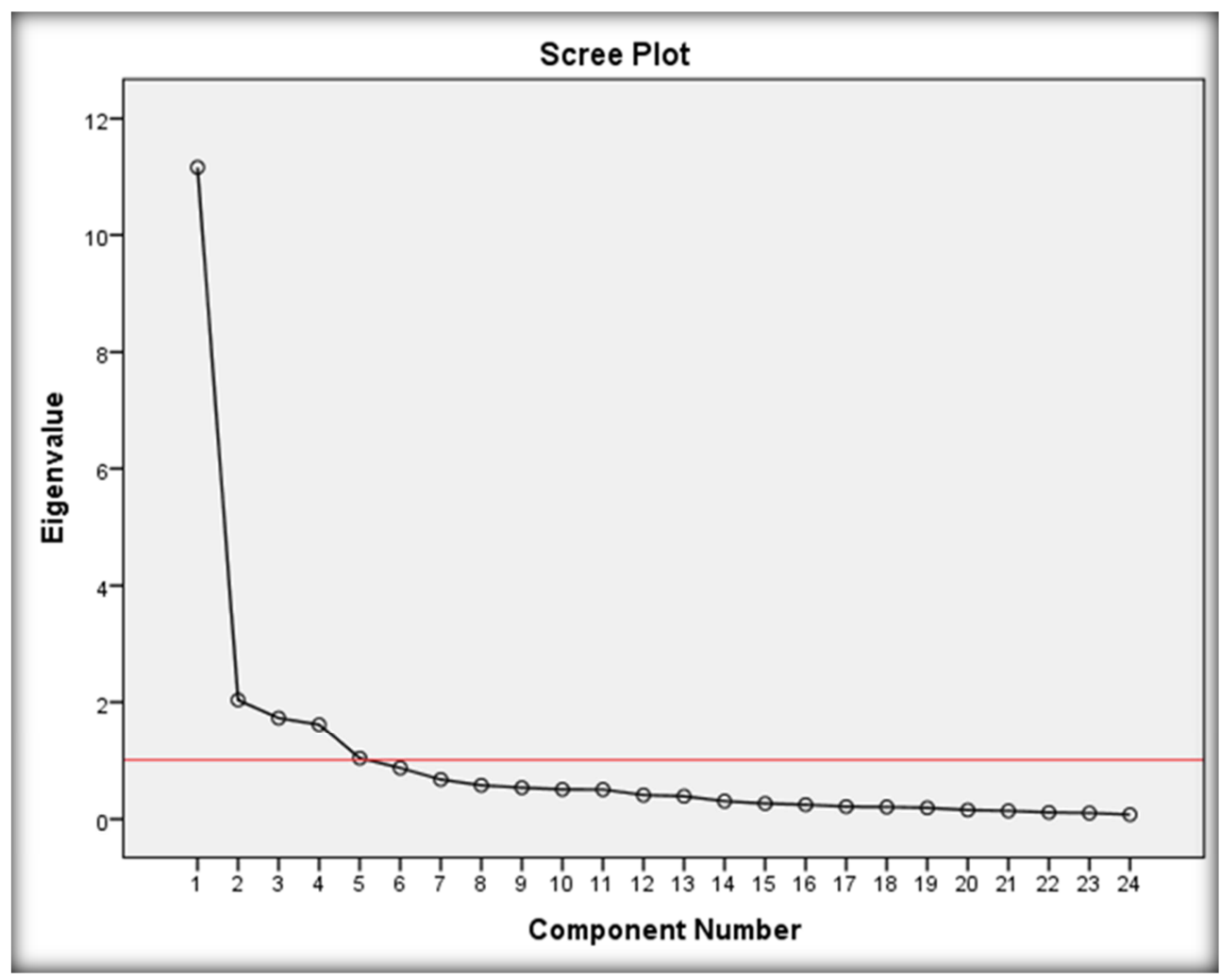

Figure 2. Scree Plot obtained from PCA analysis.

A scree plot graphs the amount of variation explained by each component. From Figure 2, it is seen that only five components' Eigen values lie above 1 and rest of them are not. Thus, it can be predicted that there are five components that can explain the variation of data set to a specific extent. This finding also supports the result obtained from Table 5.

Table 6. Rotated Component Matrix obtained from PCA analysis.

\begin{tabular}{|c|c|c|c|c|c|}
\hline \multicolumn{6}{|l|}{ Rotated Component Matrix } \\
\hline & \multicolumn{5}{|c|}{ Component } \\
\hline & 1 & 2 & 3 & 4 & 5 \\
\hline Willingness attitude of doctor & .769 & .111 & .265 & .146 & -.093 \\
\hline Getting adequate information of health condition & 693 & .276 & .299 & .049 & .235 \\
\hline Professionalism attitude of staffs & 687 & .391 & .027 & -.040 & .096 \\
\hline Competency of nurses & 677 & .265 & .393 & -.113 & -.095 \\
\hline Correctness of medical process at the first time & 673 & .191 & .291 & -.140 & .308 \\
\hline Maintenance of cleanliness & 637 & .234 & .529 & .046 & .044 \\
\hline Competency of doctor & .581 & .220 & .190 & -.135 & .251 \\
\hline Efficiency of provided service & .579 & .357 & .416 & .019 & .373 \\
\hline Disciplined attitude of staffs & .533 & .364 & .389 & -.058 & .392 \\
\hline Caring attitude of staffs & .294 & .787 & .158 & .078 & .153 \\
\hline Helpful attitude of stuffs & .255 & .735 & .119 & -.075 & .325 \\
\hline Polite attitude of staffs & .399 & .716 & .114 & .006 & -.064 \\
\hline Response attitude of staffs & .221 & .706 & .326 & -.017 & .181 \\
\hline Responsiveness of staffs & -.023 & .687 & .359 & .000 & -.131 \\
\hline Providing service with prompt responsiveness & .341 & .684 & .247 & -.062 & -.108 \\
\hline Sufficiency of skilled stuffs & .477 & .510 & .434 & -.005 & -.085 \\
\hline Cleanliness of cabins & .240 & .197 & .852 & .092 & .021 \\
\hline Cleanliness of toilet & .253 & .262 & .815 & -.074 & .018 \\
\hline Maintenance of rules & .254 & .293 & .771 & -.151 & -.011 \\
\hline Clean appearance of hospital staffs & .426 & .205 & .694 & -.027 & .027 \\
\hline Getting adequate information of treatment & .417 & .243 & .494 & .084 & .486 \\
\hline Expectation of tips of hospital staffs & .011 & .048 & -.094 & .949 & -.035 \\
\hline Providing service properly without tips & -.053 & -.067 & .032 & .948 & -.059 \\
\hline Getting adequate information of undergoing test & .094 & -.038 & -.115 & -.098 & .928 \\
\hline
\end{tabular}

Table 6 presents rotated component matrix which shows

the correlation between the obtained five factors and related 
variables considered in the study. The table shows that the first factor is highly correlated with nine variables: willingness attitude of doctor, getting adequate information of health condition, professionalism attitude of staffs, competency of nurses, correctness of medical process at the first time, maintenance of cleanliness, competency of doctor, efficiency of provided service, and disciplined attitude of staffs. So, these nine variables are included in the first factor. The second factor is strongly correlated with seven variables: caring attitude of staffs, helpful attitude of stuffs, polite attitude of staffs, response attitude of staffs, responsiveness of staffs, providing service with prompt responsiveness, and sufficiency of skilled stuff. These variables are included in the second factor. Now, the third factor is highly correlated with five variables: cleanliness of cabins, cleanliness of toilet, maintenance of rules, clean appearance of hospital staffs, and getting adequate information of treatment.

The table 6 indicates that the fourth factor is highly correlated with two variables: expectation of tips of hospital staffs, providing service properly without tips. Lastly, from the above table, it can be seen that the fifth factor has strong correlation with only one variable: getting adequate information of undergoing test. So, this variable is being included in the fifth factor. The above factors can be presented as:

Table 7. Including original variables as factors.

\begin{tabular}{ll}
\hline Factors & Included variables \\
\hline Factor 1 & $\begin{array}{l}\text { Willingness attitude of doctor, Getting adequate information of health condition, Professionalism attitude of staffs, Competency of nurses, } \\
\text { Correctness of medical process at the first time, Maintenance of cleanliness, Competency of doctor, Efficiency of provided service, } \\
\text { Disciplined attitude of staffs. }\end{array}$ \\
Factor 2 & $\begin{array}{l}\text { Caring attitude of staffs, Helpful attitude of stuffs, Polite attitude of staffs, Response attitude of staffs, Responsiveness of staffs, Providing } \\
\text { service with prompt responsiveness, Sufficiency of skilled stuffs. }\end{array}$ \\
Factor 3 & $\begin{array}{l}\text { Cleanliness of cabins, Cleanliness of toilet, Maintenance of rules, Clean appearance of hospital staffs, Getting adequate information of } \\
\text { treatment. }\end{array}$ \\
Factor 4 & $\begin{array}{l}\text { Expectation of tips of hospital staffs, Providing service properly without tips. } \\
\text { Factor } 5\end{array}$ \\
\hline
\end{tabular}

Table 8. Poisson log linear model estimates of the selected covariates for the number of hospital visit (s) per year by heart disease patients in Dhaka city along with standard error (SE), and p-value.

\begin{tabular}{|c|c|c|c|}
\hline Covariates & coefficient & SE & P-value \\
\hline Intercept & 1.005 & 0.102 & 0 \\
\hline \multicolumn{4}{|l|}{ Relative in Dhaka } \\
\hline no & -0.246 & 0.094 & 0.009 \\
\hline yes & - & - & - \\
\hline \multicolumn{4}{|l|}{ Heart condition } \\
\hline not satisfactory & 0.274 & 0.108 & 0.011 \\
\hline satisfactory & - & - & - \\
\hline \multicolumn{4}{|l|}{ Surgery taking } \\
\hline no & -0.205 & 0.087 & 0.019 \\
\hline yes & - & - & - \\
\hline \multicolumn{3}{|l|}{ Nearby hospital } & 0.008 \\
\hline far & - & - & - \\
\hline \multicolumn{4}{|l|}{ Education } \\
\hline illiterate & -0.541 & 0.293 & 0.064 \\
\hline primary & -0.269 & 0.136 & 0.047 \\
\hline $\mathrm{SSC}$ & -0.016 & 0.111 & 0.886 \\
\hline HSC & 0.05 & 0.11 & 0.646 \\
\hline Higher & - & - & - \\
\hline Per visit cost & $<0.001$ & $<0.001$ & 0.781 \\
\hline
\end{tabular}

The significant variables that are affecting the number of hospital visit (s) per year for heart disease are shown in Table 8. The variables relative in Dhaka, heart condition surgery taking, nearby hospital and education were found significant in the Table while per visit cost was insignificant in the model. The analysis reveals that having relative in Dhaka is highly significant at $1 \%$ significance level. The log of mean number of visits per year in hospital for the patient who hasn't relative in Dhaka is.246 unit lower than the patient who has relative in Dhaka, keeping all other covariates at fixed level. Heart condition is significantly related to hospital visiting with $p$-value 0.011 . The patient whose present heart condition isn't satisfactory has.274 unit higher mean number of visits per year in hospital than the patient whose present heart condition is satisfactory, keeping all other covariates fixed. The $\log$ of mean of number of visits per year in hospital for the patient who hasn't gone through any surgery is.205 unit less than the patient who has gone through any surgery and this relationship is statistically significant having p-value 0.019 . Distance to nearby hospital is also playing a significant role in the model with p-value 0.008 . The patient whose home isn't far from hospital has.219 unit lower log of mean number of visits per year in hospital. Education status of the patients is also a potential determinant in the model. The coefficients -0.541 and -0.269 mean that $\log$ of mean of number of visits per year in hospital for those patients who are illiterate and who have completed their education level up to primary are 0.541 and.269 unit lower, respectively, than the patients whose educational qualification is higher.

\section{Conclusion}

The study identified the potential elements of patients' concern in hospital services. The first factor is hospital maintenance, if hospital authority focuses on the maintenance of cleanliness through overall system, correctness of medical process at the first time, giving adequate information to the patients of their health condition, the patients will be satisfied. Again, if hospital staffs are professional, nurses and doctors are competent and doctors pay more attention to the patients, the patients are highly satisfied with the hospital services. When a patient is sick, he needs not only treatment but also extra care and affectionate behavior. Sometimes, polite behavior may help them release tension, anxiety which are harmful to heart diseased patient. That is why, the second factor emphasizes on competency, polite, and helpful attitude 
of stuffs. On the propensity to seek baksheesh, however, it is surprising that it takes place on the fourth factor, i.e., patients' concern on baksheesh is less. Perhaps this reflects the general social malaise that pervades the context of transactions: people simply do not expect to get due services without paying baksheesh. The last factor is on patients' demand on getting adequate information of undergoing tests. The study found ultimate dissatisfaction of the patients which brings the thought that a powerful managerial orientation might be launched in the hospitals to ensure quality services.

\section{References}

[1] Andaleeb SS. Service quality in public and private hospitals in urban Bangladesh: a comparative study. Health Policy. 2000; 53 (1): $25-37$

[2] Riaz BK, Selim S, Karim MN, Chowdhury KN, Chowdhury $\mathrm{SH}$, Rahman MR. Risk factors of rheumatic heart disease in Bangladesh: a case-control study. Journal of health, population, and nutrition. 2013; 31 (1): 70.

[3] Muhit MA, Rahman MO, Raihan SZ, Asaduzzaman M, Akbar MA, Sharmin N, et al. Cardiovascular disease prevalence and prescription patterns at a tertiary level hospital in Bangladesh. Journal of Applied Pharmaceutical Science. 2012; 2 (3): 8.

[4] Rahman M, Zaman MM, Islam JY, Chowdhury J, Ahsan HN, Rahman R, et al. Prevalence, treatment patterns, and risk factors of hypertension and pre-hypertension among Bangladeshi adults. Journal of human hypertension. 2018; 32 (5): 334-48.

[5] Zaman MM, Choudhury SR, Ahmed J, Khandaker RK, Rouf MA, Malik A. Salt intake in an adult population of Bangladesh. Global heart. 2017; 12 (3): 265.

[6] Chowdhury MZI, Haque MA, Farhana Z, Anik AM, Chowdhury AH, Haque SM, et al. Prevalence of cardiovascular disease among Bangladeshi adult population: a systematic review and meta-analysis of the studies. Vascular health and risk management. 2018; 14: 165.

[7] Zeileis A, Hothorn T. Diagnostic checking in regression relationships. 2002.

[8] Draper NR, Smith H. Applied regression analysis: John Wiley \& Sons; 1998.

[9] Fahrmeir L, Kneib T, Lang S, Marx B. Regression models. Regression: Springer; 2013. p. 21-72.

[10] Montgomery DC, Peck EA, Vining GG. Introduction to linear regression analysis: John Wiley \& Sons; 2012.
[11] Saber AY, Alam AR, editors. Short term load forecasting using multiple linear regression for big data. 2017 IEEE Symposium Series on Computational Intelligence (SSCI); 2017: IEEE.

[12] Sarkar S, Midi H. Importance of assessing the model adequacy of binary logistic regression. Journal of Applied Sciences. 2010; 10 (6): 479-86.

[13] Myung IJ. Tutorial on maximum likelihood estimation. Journal of mathematical Psychology. 2003; 47 (1): 90-100.

[14] Albert A, Anderson JA. On the existence of maximum likelihood estimates in logistic regression models. Biometrika. 1984; 71 (1): 1-10.

[15] Buttle F. SERVQUAL: review, critique, research agenda. European Journal of marketing. 1996.

[16] Oh H, Parks SC. Customer satisfaction and service quality: a critical review of the literature and research implications for the hospitality industry. Hospitality Research Journal. 1996; 20 (3): 35-64

[17] Cronin Jr JJ, Taylor SA. Measuring service quality: a reexamination and extension. Journal of marketing. 1992; 56 (3): 55-68.

[18] Carman JM. Consumer perceptions of service quality: an assessment of T. Journal of retailing. 1990; 66 (1): 33.

[19] Andaleeb SS, Basu AK. Technical complexity and consumer knowledge as moderators of service quality evaluation in the automobile service industry. Journal of retailing. 1994; 70 (4): 367-81.

[20] Reidenbach RE, Sandifer-Smallwood B. Exploring perceptions of hospital operations by a modified SERVQUAL approach. Marketing Health Services. 1990; 10 (4): 47.

[21] Wold S, Esbensen K, Geladi P. Principal component analysis. Chemometrics and intelligent laboratory systems. 1987; 2 (13): $37-52$.

[22] Thomaz CE, Giraldi GA. A new ranking method for principal components analysis and its application to face image analysis. Image and Vision Computing. 2010; 28 (6): 902-13.

[23] Berk R, MacDonald JM. Overdispersion and Poisson regression. Journal of Quantitative Criminology. 2008; 24 (3): 269-84.

[24] Dietz E, Böhning D. On estimation of the Poisson parameter in zero-modified Poisson models. Computational Statistics \& Data Analysis. 2000; 34 (4): 441-59.

[25] Parasuraman A, Zeithaml VA, Berry LL. A conceptual model of service quality and its implications for future research. Journal of marketing. 1985; 49 (4): 41-50. 